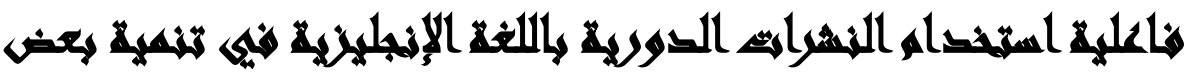

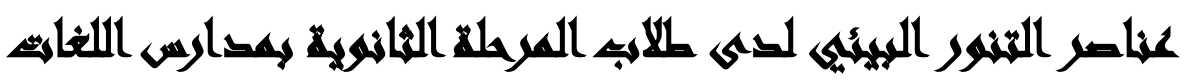
[1r]

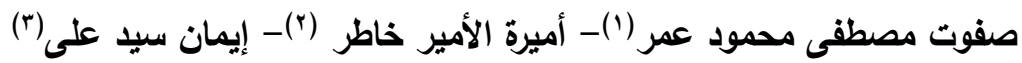

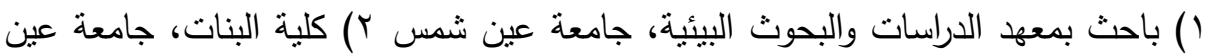

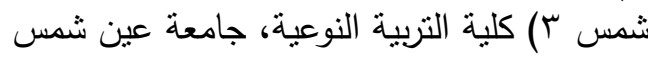

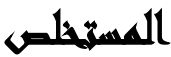

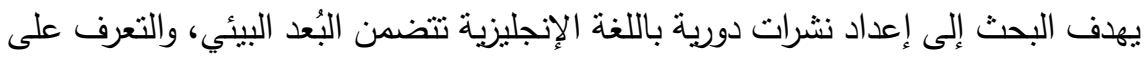

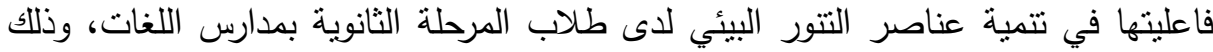

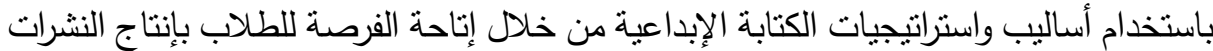

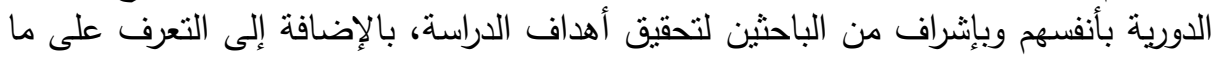

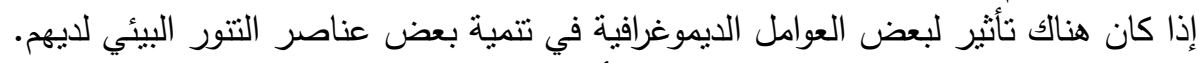

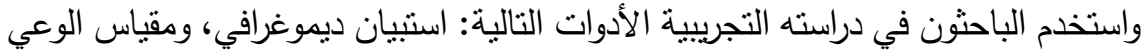

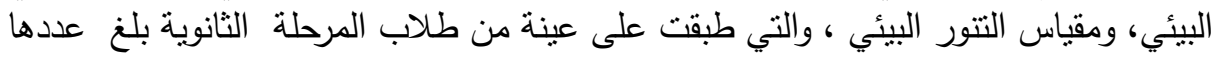

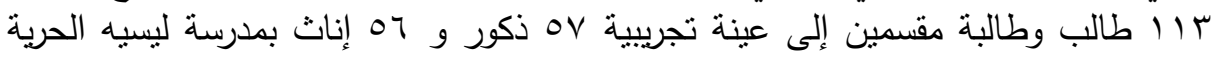

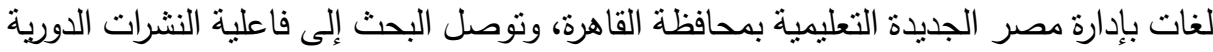

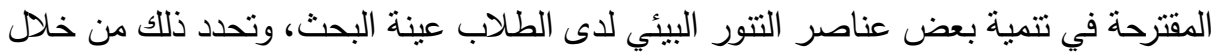

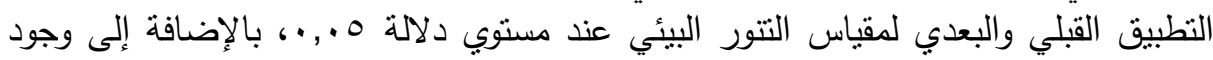

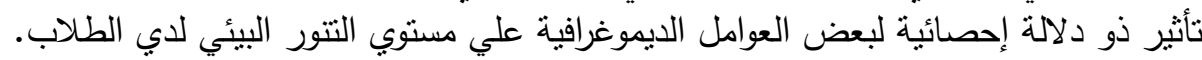

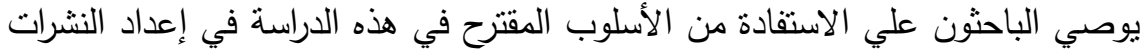

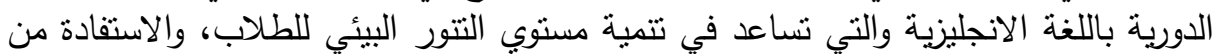

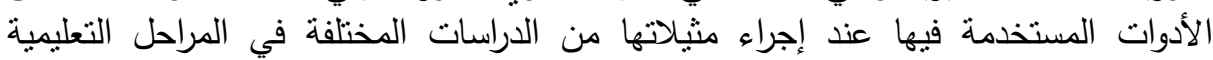

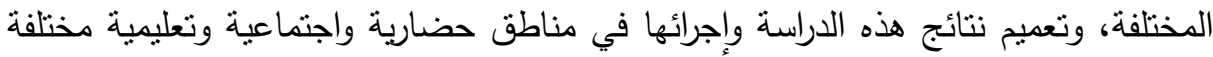
للكثثف عن العوامل المختلفة التي تعمل علي تتمية مستوي التتور البيئي للطلاب.

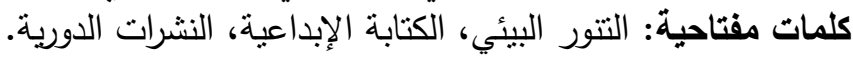




\section{ramall}

تدهورت العلاقة بين الإنسان والبيئة في الآونة الاخيرة الى درجة لا تحتمل التجاهل واصبح

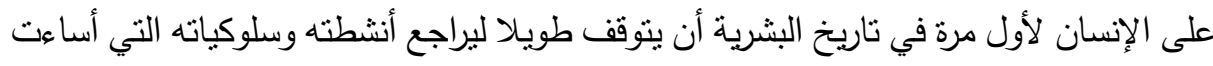

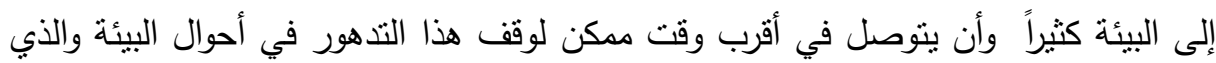
يؤثر علي الحياة في كوكب الأرض.

ولقد أكدت الدراسات والبحوث والندوات في مجال البيئة على كافة المسنويات المحلية والعربية والعالمية أن الاهتمام بالبيئة وصيانتها من كل ما يحدث بها من مخاطر يسببها الإنسان

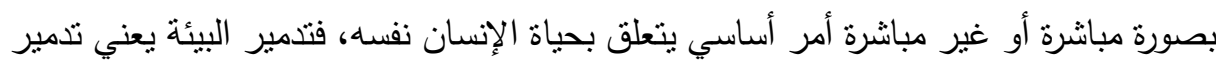
حياة الإنسان، والمحافظة على البيئة تعني الرخاء والتقدم لحياة الإنسان في حاضره ومستقبله (رضوان، 9 . . r، ص r T)، ولقد ادركت دول العالم ان المداخل الرئيسية لحل المشكلات البيئية تكمن في مشاركة المواطنين على شتى المستويات ومدى فهمه وإدراكهم للعلاقات القائمة بين

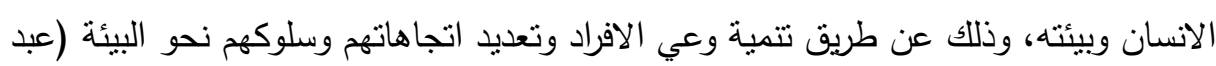

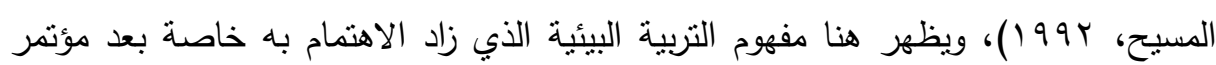
ستوكهولم الذي عقد عام 19Vr حول التربية البيئية. ولقد تعددت الآراء في مفهوم التربية البيئية ومعناها، باعتبارها مفهوماً تربوياً حديثا نسبياً نتج عن تفاعل معنى التربية والبيئة، ولذلك تعددت معاني هذا المفهوم بتعدد العملية التربوية

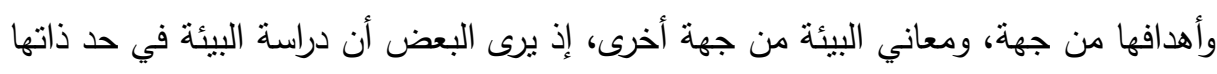

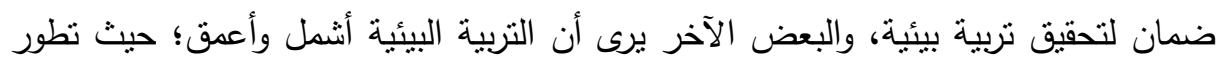

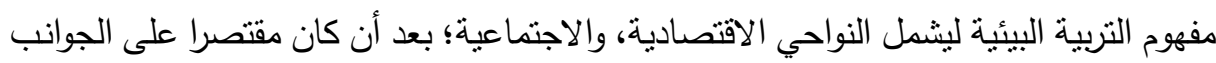

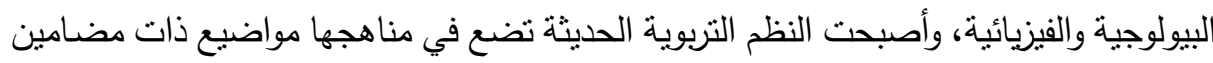
لها علاقة بالبيئة، مع إعطاء الأولوية للمشكلات التي تتعلق بكيفية حماية الموارد الطبيعية،

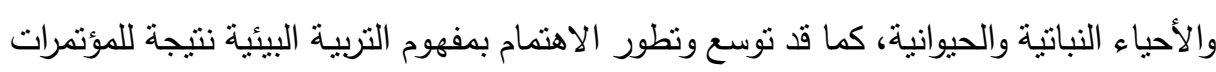

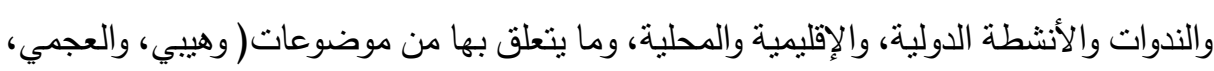


وقد حددت اليونسكو(990 (1) غايات التربية البيئية في المجالات التالية: 1- الوعي: مساعدة الأفراد على اكتساب الوعي والحساسية إزاء البيئة ومشكلاتها.

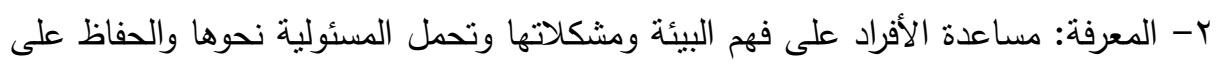
مواردها ومكوناتها r- المواقف: مساعدة الأفراد على اكتساب القيم الاجتماعية والمشاعر الايجابية للاهتمام بالبيئة وحمايتها.

ع - المهارات: مساعدة الأفراد على اكتساب المهارات اللازمة للإسهام في حل المشكلات البيئية.

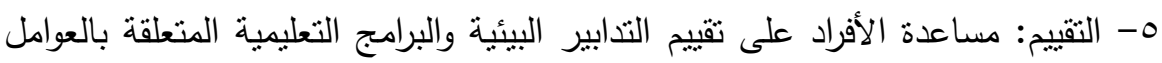
البيئية والسياسية والاقتصادية والاجتماعية والجمالية.

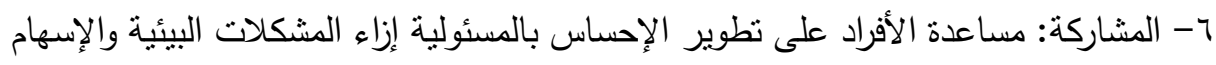

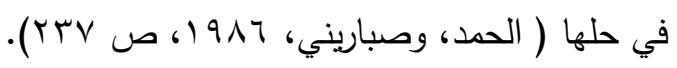
والتربية البيئية مدخل هام لترشيد وتهذيب سلوك الإنسان نحو البيئة ومواردها ومكوناتها

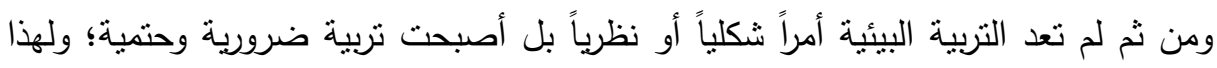
ازداد اهتمام الدول المتقدمة والنامية على السواء بتضمين التربية البيئية في برامج التعليم العام تصنية

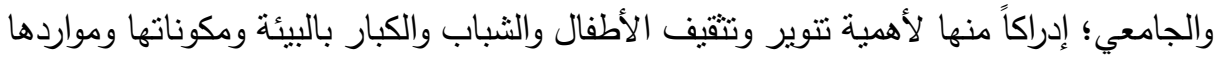
وخطورة المشكلات البيئية على حياتهم في الحاضر والمستقبل. والتتوير والتثقيف البيئي للطلاب يمكن أن يتحقق من خلال البرامج الدراسية إذا تم اختيار وتحديد المحتوى المناسب وكذلك أساليب التدريس والأنشطة والوسائل التعليمية و أساليب ووسائل التقويم المناسبة( عبد السلام، ب . . r) ، ومن ثم نستطيع القول بأن الغاية الأسمى للتربية البيئية هي تتمية التتور البيئي لدي أفراد المجتمع بمختلف الطبقات الاجتماعية والعمرية والاقتصادية

والمدرسة من أهم المؤسسات التي يعهد اليها المجتمع في مهمات رعاية أبنائهم وتتشئتهم

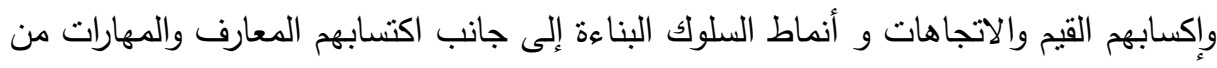
المدرسة للأهداف التربوية والتعليمية والاجتماعية التي تعمل على تحقيقها في خدمة البيائة 
والمجتمع، وقد ظهرت الاتجاهات الحديثة في التربية التي ترمي إلى ربط المدرسة بالبيئة المحيطة وربط البيئة بالمدرسة وقد ادخلت العديد من دول العالم برامج مجانية في التربية البيئية في

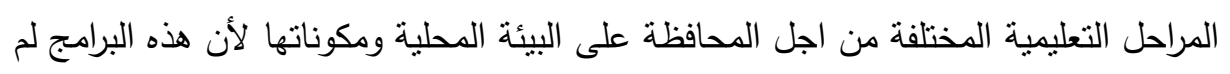

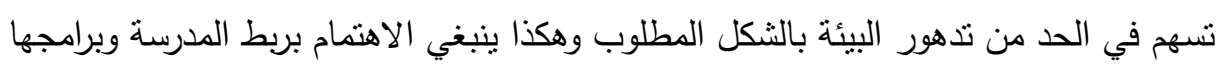

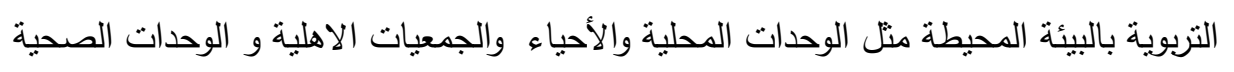

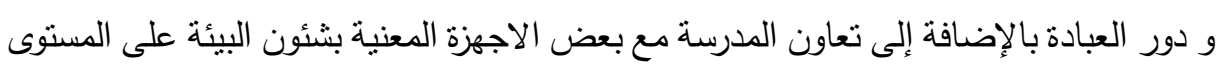

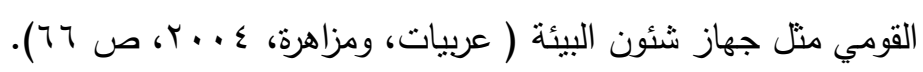
ومهمة المؤسسة التربوية واسعة ومتتوعة، مما زاد في الحاجة إلى الإعلام التربوي عموما

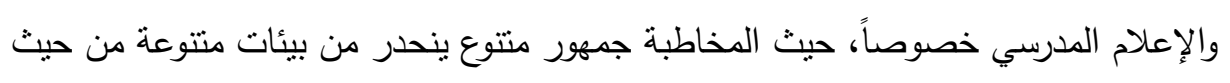

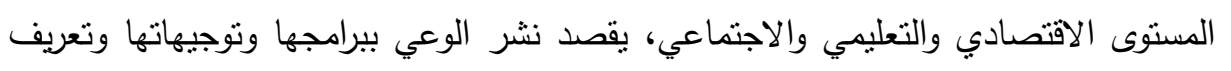

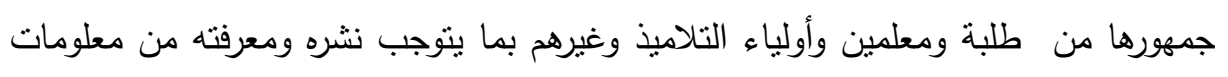

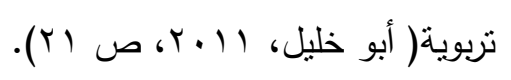

والإعلام المدرسي نشاط كتابي أو شفهي يقوم به التلميذ داخل مدرسته عبر أوجه عديدة

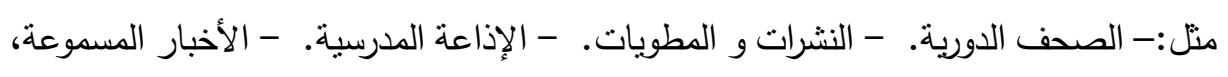

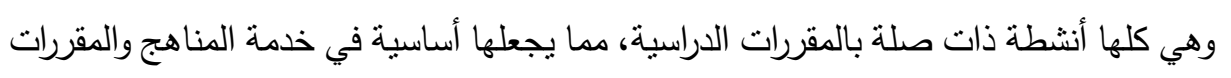
الدراسية. ولأن الددرسة هي المؤسسة التربوية الاجتماعية التي نسعى الى تحقيق النمو المتكامل

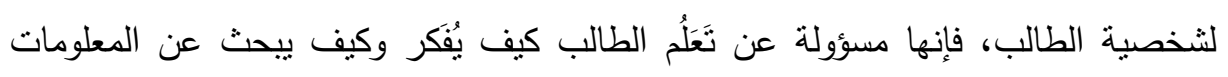

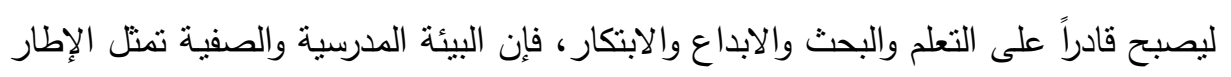

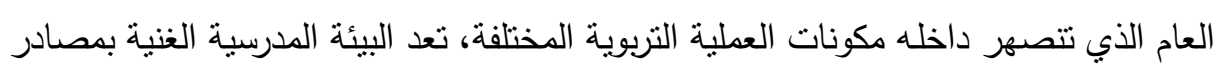
التعلم وفرص اكتشاف ما لدى الطلبة من استعدادات واهتمامات بمثابة البنية التحنية لبرامج المدرسة التي تهدف إلى تتمية التفكير والإبداع، فلم يعد دور المدرسة يقتصر كمؤسسة تعليمية فقط لكن أصبح لها دور كبير كمؤسسة تربوية في خلق السلوكيات الايجابية وتربية النشأ وتعليمه تهنه

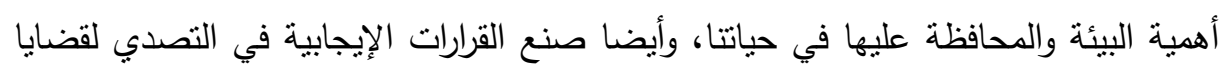
بيئية حساسة نتيجة حسهم ووعيهم البيئي الذي غرسته فيهم المدرسة منذ النشء. 
مما نقدم تبين أن هناك حاجة ماسة وملحة إلى تربية تعد الفرد المتقهم لبيئته والمدرك لظروفها والواعي بما تواجهها من مشكلات وما يهددها من أخطار والقادر على المساهمة

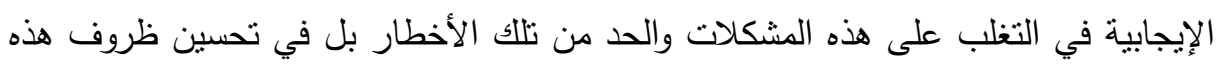

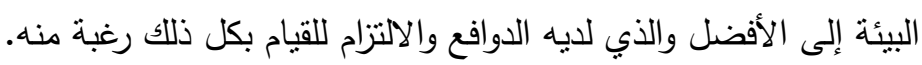

\section{Anth}

إذا كانت معظم المشكلات البيئية تعود إلى الأنماط السلوكية الخاطئة للإنسان مع البيئة

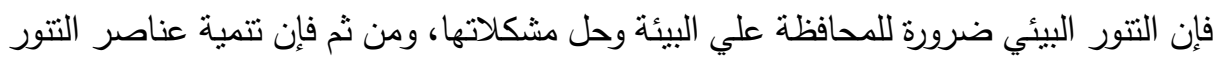

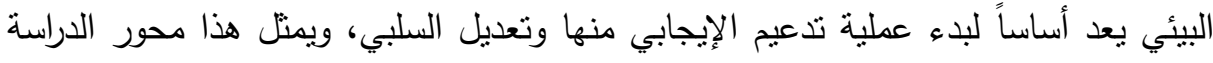

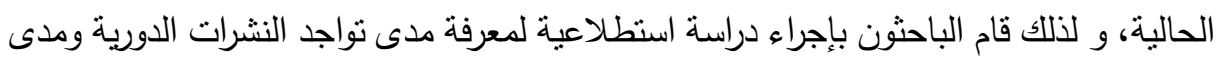

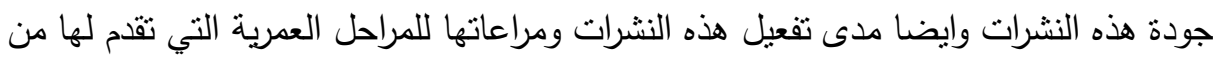

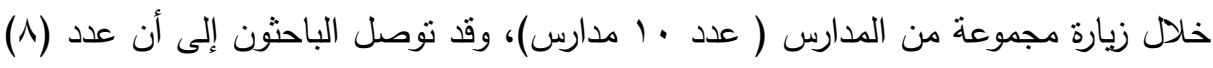

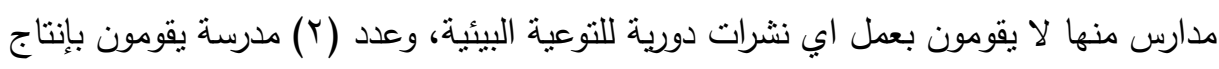

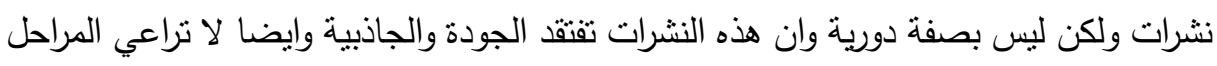

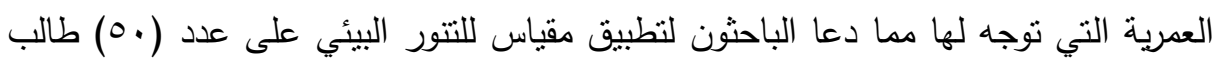
من طلاب المدارس التي بها نشرات (مدرسة ليسيه الحرية مصر الجديدة ) حيث نم تطبيق

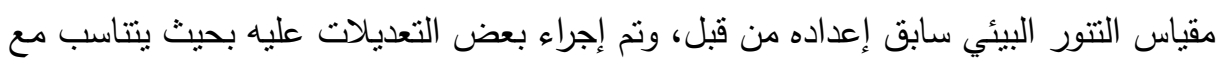

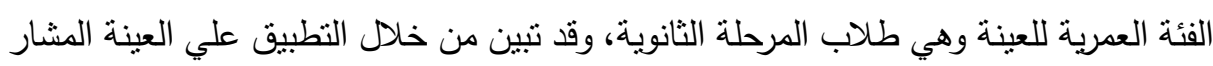

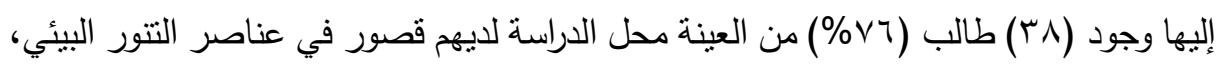
ومن هنا جاء الإحساس بمشكلة البحث وتتمنل في كيفية التغلب علي القصور في عناصر التتور البيئي لدي الطلاب، وما الذي يمكن فعله في سبيل تتمية عناصر التتور البيئي للطلاب، لإبه ومن هنا برز التساؤل الرئيس الذي تحاول الدراسة الحالية الإجابة عليه وهو كالتالي:

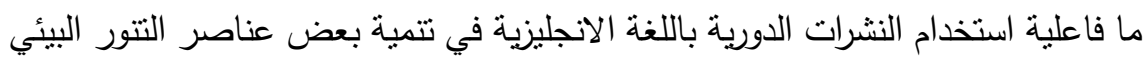

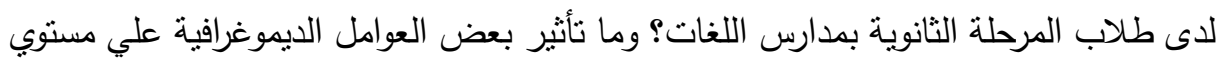
التتور البيئي لدي الطلاب؟ 


\section{أسئلا الهمبه}

في ضوء مشكلة البحث صيغت النساؤلات النالية: 1-ما القضايا البيئية التي ينبغي تقديمها لطلاب المرحلة الثانوية بدارس اللغاتهات

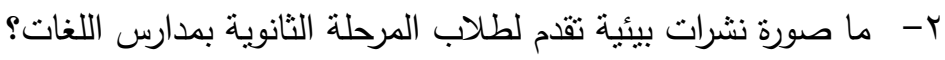

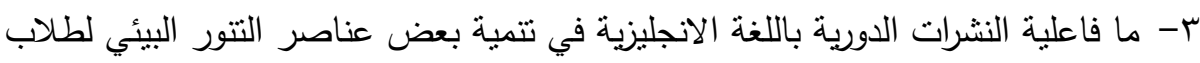

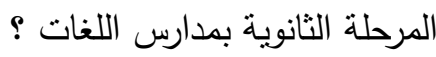

\section{أهما اهن المهمث}

$$
\text { يهدف البحث إلى: }
$$

1-تتمية بعض عناصر التتور البيئي لاى طلاب مدارس اللغات بتضمين البعد البيئي في

$$
\text { النشرات الدورية التي تقدم باللغة الإنجليزية. }
$$

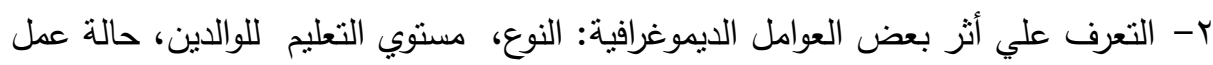

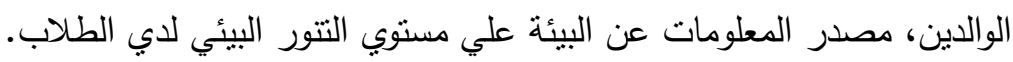

\section{هروغ اللهمهي}

1-توجد فروق ذات دلالة إحصائية بين متوسط الدرجات الكلية للطلاب بين النطبيق القبلي

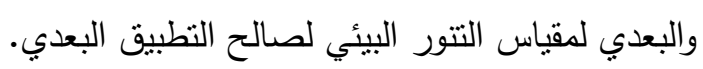

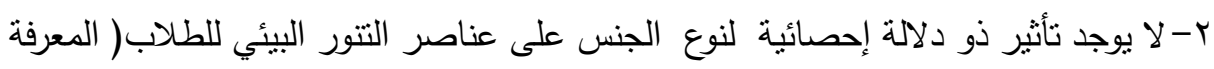
والاتجاهات والحساسية والاهتمام). ب- لا يوجد نأثير ذو دلالة إحصائية للمستوى التعليمي لأمهات الطلاب علي مستوي التتور

$$
\text { البيئي لأبنائهم الطلاب. }
$$

ع-ليس هناك تأثير كبير للمستوى التعليمي لآباء الطلاب علي مستوي التنور البيئي لأبنائهم

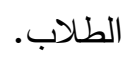

0- لا يوجد تأثير كبير لحالة عمل الأمهات علي مستوي التتور البيئي للطلاب. צ- ليس هناك تأثير كبير لحالة عمل الآباء علي مستوي التتور البيئي للطلاب. 


\section{مشوض المجهي}

حدود بشرية: نطبق الدراسة على عينة من الطلاب بالمرحلة الثانوية بمدارس اللغات (مدرسة

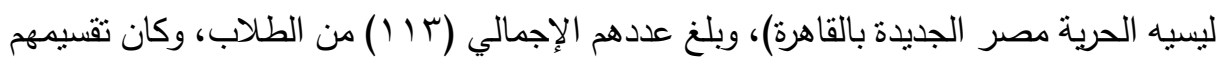

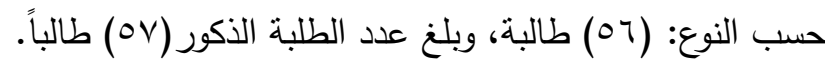

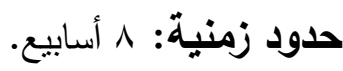
حدود مكانية: مدرسة ليسيه الحرية لغات بإدارة مصر الجديدة التعليمية بمحافظة القاهرة.

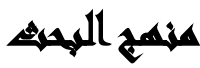

استخدم الباحثون المنهج الوصفي في تحليل استبيان ديموغرافي لبعض العوامل

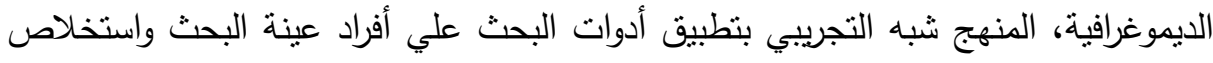

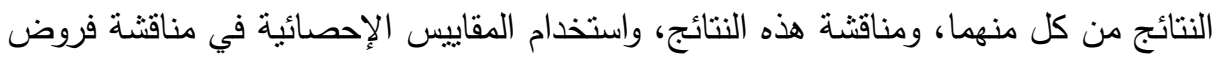
البحث.

\section{مسطلحاهي الهمبه}

التتور البيئي (Environmental Literacy) : كل ما يكتسبه الفرد من معلومات ومهارات واتجاهات ومعتقدات وقيم تمكنه من حسن التصرف مع البيئة والمحافظة عليها وتطويرها

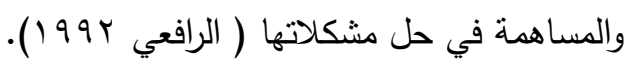

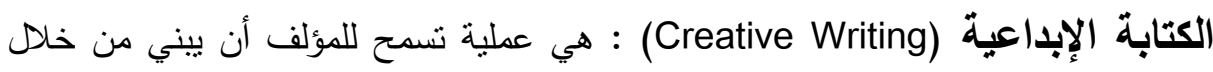

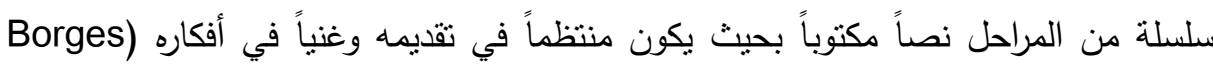

النشرات الدورية (Periodicals) : هي سلسلة في أجزاء، وعادة تحتوي على مقالات لكتاب

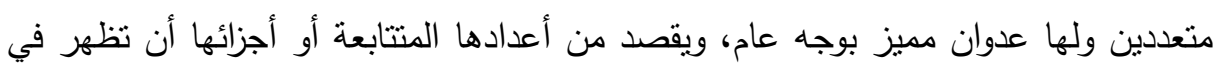

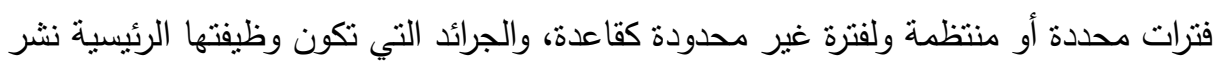


الأخبار، والمذكرات، وأعمال المؤتمرات... إلخ لا تعتبر دوريات وفقاً لقواعد الفهرسة(A.L.A. () (19VT

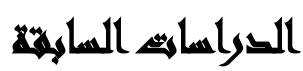

أجريت عدة دراسات في إطار متغيرات الدراسة الحالية منها ما يتتاول تقييم مستويات او عناصر التتور البيئي، وبعضها نتاول المحور الثناني وهو الكتابة الإبداعية، بالإضافة لدراسات

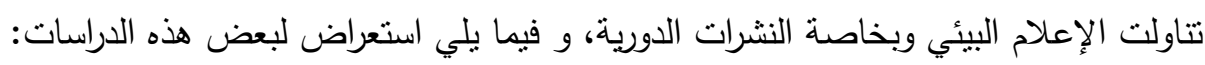

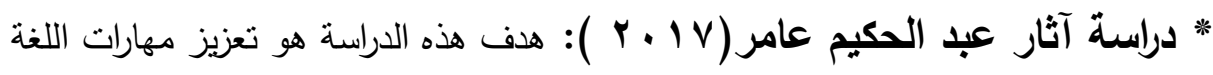
الإنجليزية كلغة أجنبية للمرحلة الثانوية للصف الثاني الثانوي، والكتابة الإبداعية ومهارات حل المشكلات من خلال برنامج التعلم القائم على حل المشكلات، شمل المشاركون في الإنه

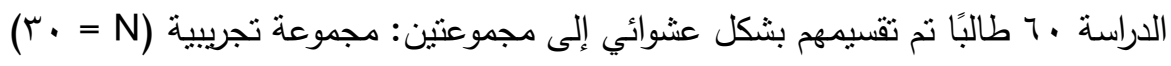
ومجموعة ضابطة (N N N . N)، تلقت المجموعة التجريبية تعليمات باستخدام برنامج تعلم

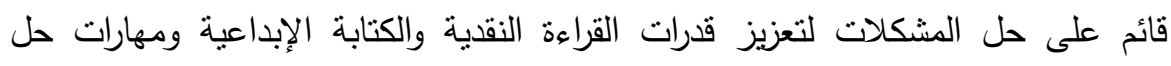
المشكلات، من ناحية أخرى تلقى طلاب المجموعة الضابطة تعليماتهم العادية. كانت أدوات الدراسة عبارة عن: قراءة نقدية للغة الإنجليزية كلغة أجنبية، ومقياس الكتابة الإبداعية،

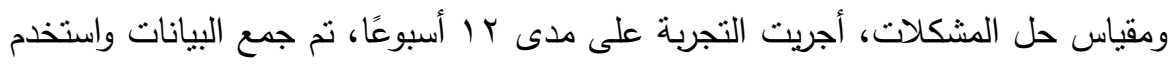

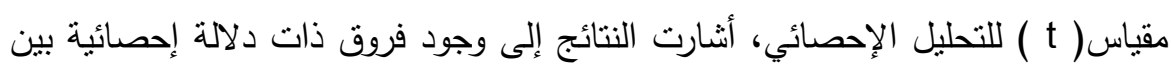
منوسطات درجات المجموعة التجريبية ودرجات المجموعة الضابطة في القراءة النقدية، والكتابة الإبداعية ومهارات حل المشكلات لصالح المجموعة التجريبية. * دراسة غزيل محمد غصن العجمي(؟ ا م ب): هدف البحث إلي تتمية بعض عناصر

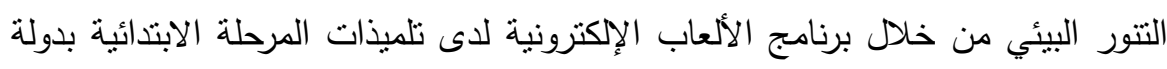
الكويت، استخدمت الباحثة المنهج الوصفي في تحليل محتوى المنهج الدراسي، والمنهج

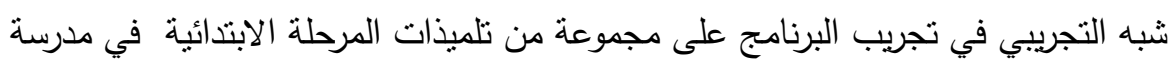

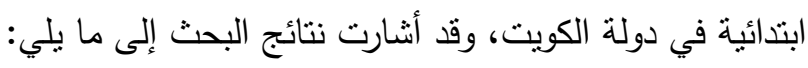


1- نوجد فروق ذات دلالة إحصائية عند مستوى ه., · بين متوسط درجات تلميذات المجموعة التجريبية ودرجات تلميذات المجموعة الضابطة بالنسبة لمقياس الاتجاهات البيئية في التطبيق البعدي لصالح المجموعة التجريبية التي درست البرنامج باستخدام الالعاب

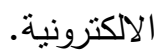

ץ- توجد فروق ذات دلالة إحصائية عند مستوىه . , • بين منوسط درجات تلميذات المجموعة

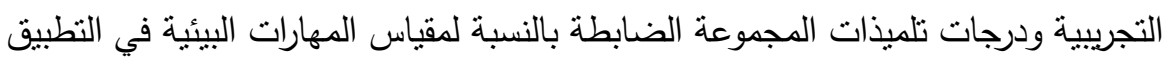
البعدي لصالح المجموعة التجريبية التي درست البرنامج باستخدام الالعاب الإكترونية.

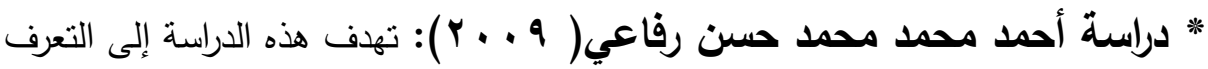
على تأثثر مجلات الأطفال الإكترونية في تتمية القدرات الإبداعية لاى أطفال الحلقة الأولي من التعليم الأساسي من(^- r I سنة) ، واعتمدت الدراسة على المنهج التجريبي باستخدام مجموعتين إحداهما ضابطة والأخرى تجريبية ، وقد أجريت الدراسة على عينة قوامها (· (7)

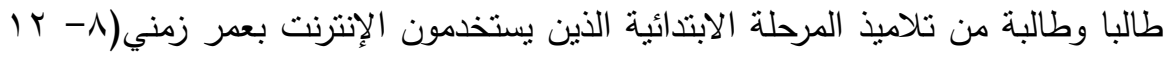

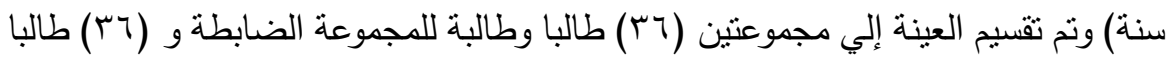
وطالبة للمجموعة التجريبية التي أجريت عليها الدراسة مع مراعاة التجانس بين المجموعتين من حيث (النوع والسن والذكاء والمستوى الاقتصادي) ، وتوصلت الدراسة إلى أنه توجد درعاد

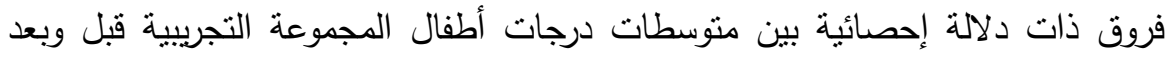

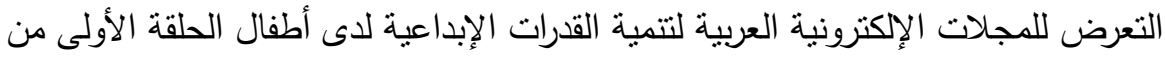
التعليم الأساسي لصالح القياس البعدي وذلك على مقياس "تورانس" للتفكير الابنكاري

$$
\text { باستخدام الصورة (ب). }
$$

\section{إلجراءايت المهيث}

الإطار النظري للبحث: يمكن استخدام الإعلام المدرسي، وأحد وسائله النشرات الدورية، منصة لتنمية عناصر التتور البيئي لدي الطلاب، ومن ثم تتمية واستكثاف قدراتهم لمواجهة

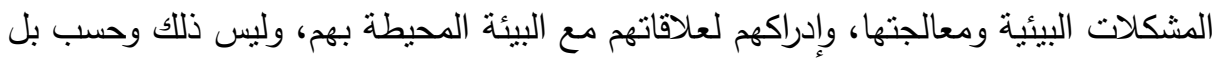
يمكن استخدام النشرات الدورية كأداة للكثف عن الجوانب الإبداعية لدي الطلاب، حيث الورئه الوسيلة 


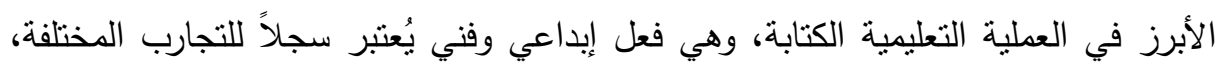

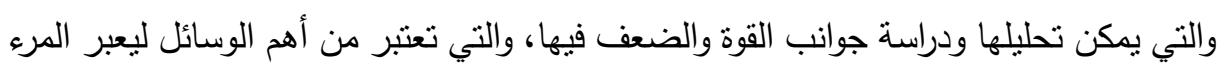
بها عن نفسه وأفكاره وتوجهاته وميوله. ومن خلال إعداد بعض الأنثطة يمكن تعزيز قدرات الطلاب علي استكثاف معارفهم

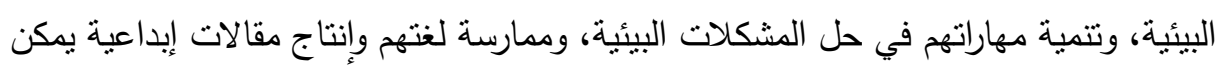

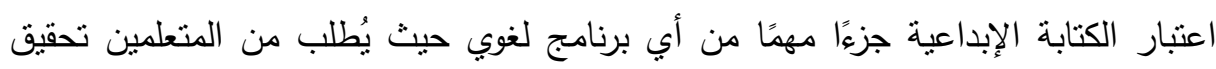
مستويات عالية من الكفاءة في اللغة التي يتم تعلمها. في ظل ذللك قام الباحثون بالإجراءات التالية:

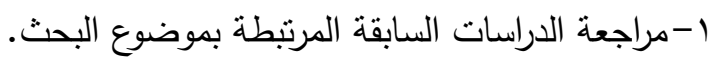

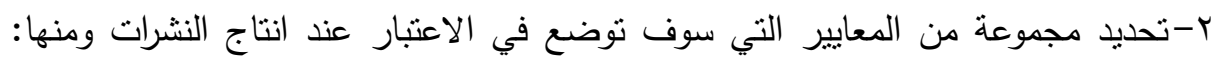

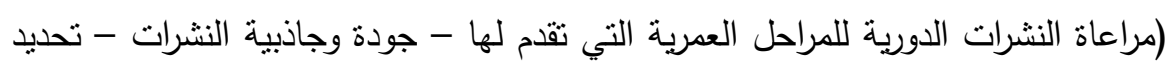

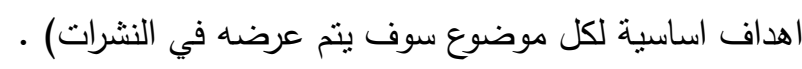

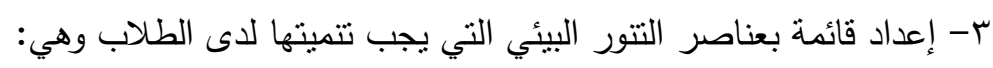

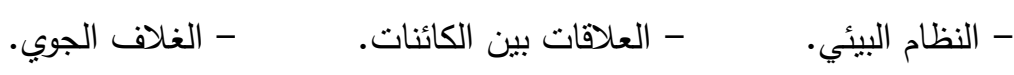

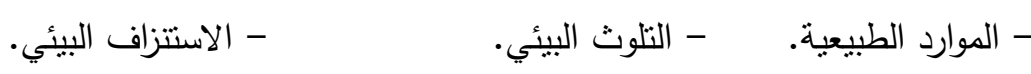
- صيانة البيئة. - متوليد الطاقة.

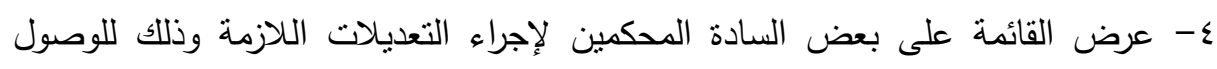
لصورتها النهائية. عينة البحث: 1- عينة ميدانية (بشرية): مجموعة من طلاب الصف المرحلة الثانوية من طلاب مدرسة

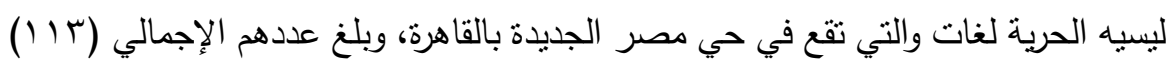

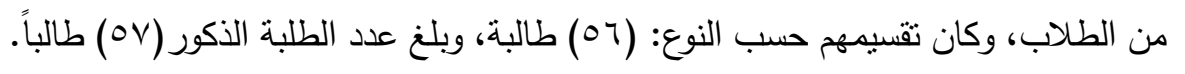

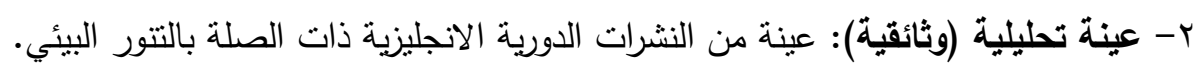


إعداد أنشطة البحث: نطبيق إعداد النشرات الدورية باللغة الإنجليزية وإنتاجها من خلال الطلبة

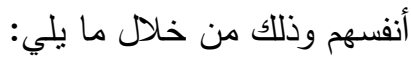

الجلسة الافتتاحية جلسة افتناحية مع الطلاب لنوضيح:

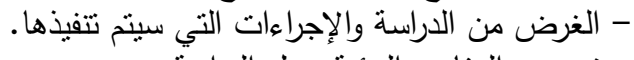

- توضيح المفاهيم البيئية محل الإدراسة.

- ترك الحرية للطلاب في اختيار استمرارهم كأفراد لعينة البحث.

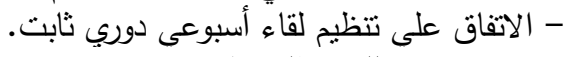
- تقديم نموذج للنشرة الدورية. - استعراض بعض نعض استراتيجيات وأساليب الكتابة الإبداعية.

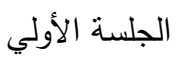
- مناقثة الاقتراحات النتظيمية التي يقدمها الطلاب. - الاتفاق علي آليات التتفيذ والمتابعة. - مناقثة الإمكانيات المتاحة لنشر النشرات النئة الدورية.

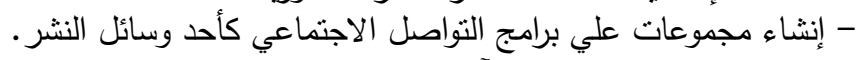

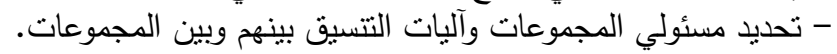
- مناقثة بعض مصادر المعلومات : مناهج دراسية- وسائل إعلام - الإنترنت مكتبة المدرسة.

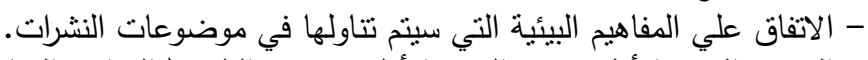

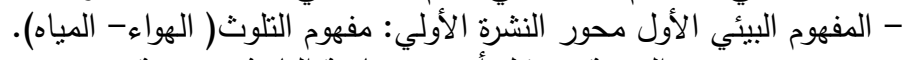

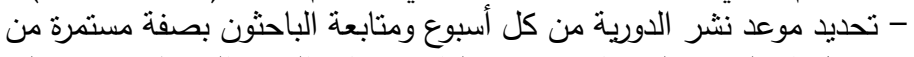
خلال الاطلاع علي ما تم من خطوات لإنتاج النشرة الدورية مع مسئولي لئية - عرض النشرة الأولي ومناقثنة العقبات والسلبيات والاعتراضات. - مناقثة الآثار المختلفة ووقعها علي الطلاب.

- الالتزام بالآليات والخطوات التي تنم الاتفاق عليها مسبقاً مع التعديلات

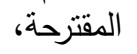

- المفهوم البيئي الثاني محور النشرة الثانية: ندرة المياهام أنواع المباه-

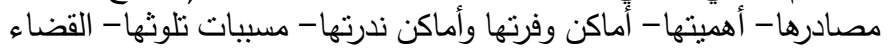
على تلك المسببات). - عرض النشرة الثانية ومناقثة العقبات والسلبيات والاعتراضات.

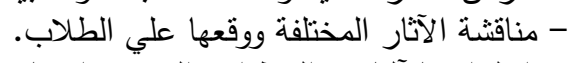

- الالتزام بالآليات والخطوات التهي تنم الاتفاق عليها مسبقاً مع التعديلات

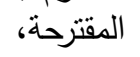

- المفهوم البيئي الثالث محور النشرة الثالثة: الششكلة السكانبة( مفهومهامسيباتها - أثزها علي البيئة- أساليب مواجهتها وعلاج آنارها). 
- عرض النشرة الثالثة ومناقنتة العقبات والسلبيات والاعتراضات.

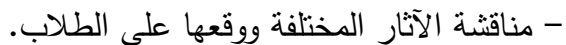
- الالتزام بالآليات والخطوات التي ثنم الاتفاق عليها مسبقاً مع التعديلات التات

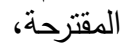

- المفهوم البيئي الرابع محور النشرة الرابعة: استتزاف الموارد الطبيعية

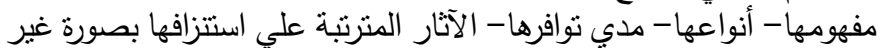
سليمة- طرق وأساليب الحفاظ عليها - طرق تتميتها).

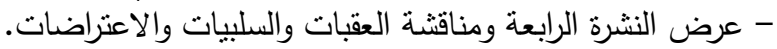
- مناقثة الآثار المختلفة وروقعها علي الرابلة الطلاب.

- الالتزام بالآليات والخطوات التي تثم الاتفاق عليها مسبقاً مع التعديلات التهات

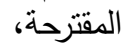

- استكثاف بعض آثار مشاركة الطلاب في إنتاج النشرات الدورية ( آثار سلوكية وبيئية- آثارها علي سلوكيات الوالدين - مدي تشجيع الوالدين - آنثارها علي زملائهم الطلاب).

-المفهوم البيئي الخامس محور النشرة الخامسة: استغلال الأراضي( أنواع

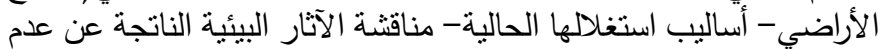
الاستغلال الأمثل لها- طرق وأساليب تتمية الرقعة الزراعية- المحافظة التهارة عليها مستقبلاً). - عرض النشرة الخامسة ومناقثة العقبات والسلبيات والاعتراضات.

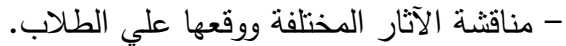

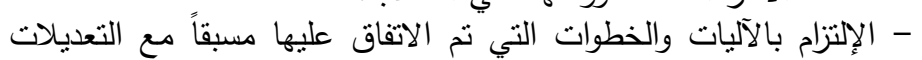

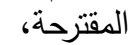
- تحفيز الطلاب واستعراض مجهوداتهم في إنتاج النشرات وشكر المتميزين - المفهوم البيئي السادس محور النشرة السادسة: التوازن البيئي( مفهومه-

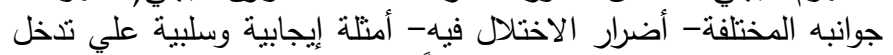
الإنسان - كيفية المحافظة عليه مستقبلاً).

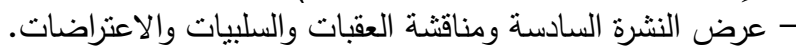

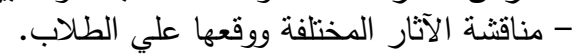
- الالتزام بالآليات والخطوات التي ثنم الاتفاق عليها مسبقاً مع التعديلات التات المقترحة، الألزام

- استعراض بعض الأدبيات التي تتاولت السلوكيات البيئية ومناقنة الطلاب فيها.

- المفهوم البيئي السابع محور النشرة السابعة: التصحر ( مفهومه- أسبابه-

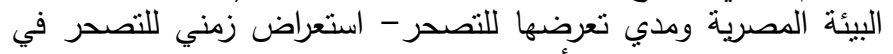

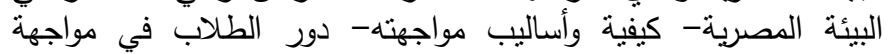

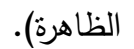

الجلسة الرابعة

الجلسة الخامسة

الجلسة السادسة 
- عرض النشرة السابعة ومناقثة العقبات والسلبيات والاعتراضات.

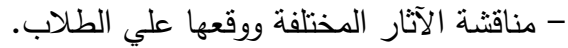
- الالتزام بالآليات والخطوات التي تنم الاتفاق عليها مسبقاً مع التعديلات التهات

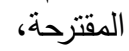

- المفهوم البيئي الثامن محور النشرة الثامنة: الصيانة البيئية( مفهومها-

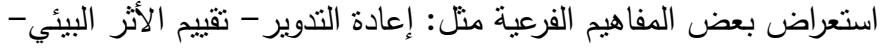

$$
\text { الرصد البيئى). (البعران. }
$$

- استعراض النشرات الدورية السابق إنتاجها.

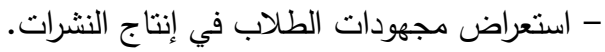

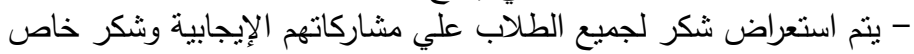

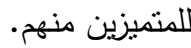

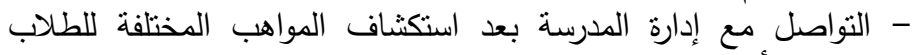
باستخدامهم أساليب واستراتيجيات الكتابة الإبداعية فى إنتاج النشرات الدورية.

-في الجلسة يتم استعراض الأعمال التي نمت بصورة تجميعية وشكر لجميع الطلاب.

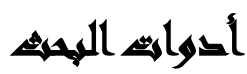

1- أدوات التجريب: إنتاج نشرات دورية انجليزية متضمنة البعد البيئي ويقوم بإنتاجها

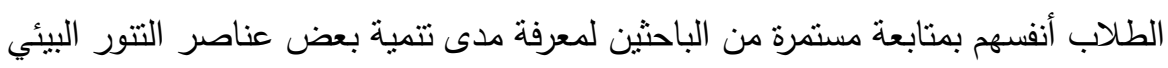

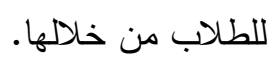

$$
\text { r - أدوات قياس وجمع البيانات: وتمنلت في ما يلي: }
$$

أ- استبيان ديموغرافي: يتكون الاستيان الديموغرافي من ستة أسئلة أسئة، تم تصميمها لتوفير بعلومات حول جنس الطلاب والسن والمستوى التعليمي للوالدين ووضع عمل التوان الوالدين.

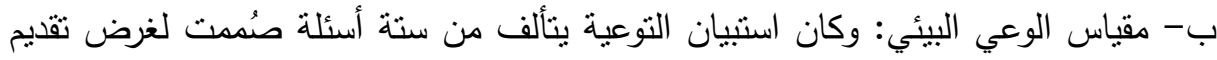

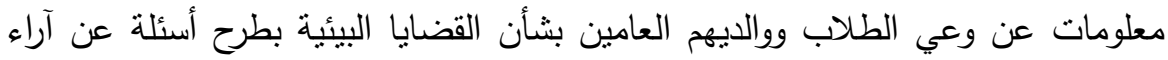
الوالدين بشأن الششاكل البيئية، سلوك الوالدين تجاه حماية البيئة ؛ الاهتمام بالهشاكل البيئية الئية

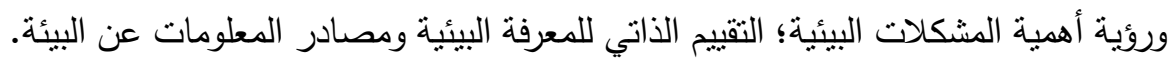

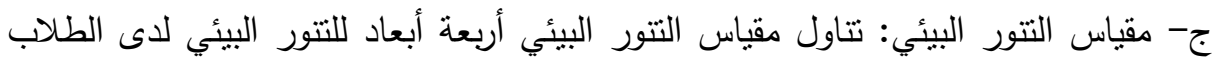

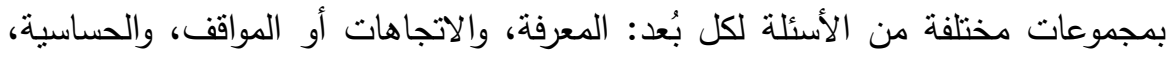


والقلق أو الاهتمام، وتم ترجمة مقياس التتور البيئي (ELT) الذي نشأ كجزء من مشروع جامعي مولته جامعة ولاية ميشيجان بالولايات المتحدة الأمريكية () (1)

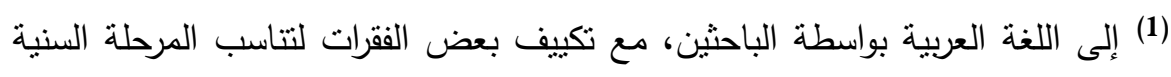

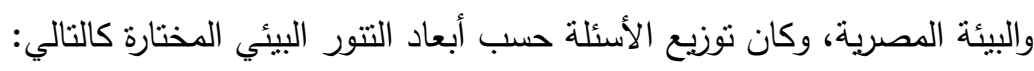

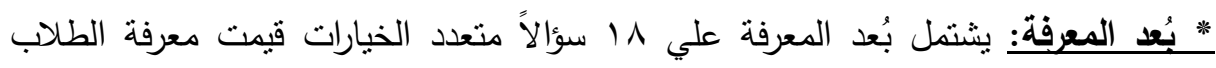

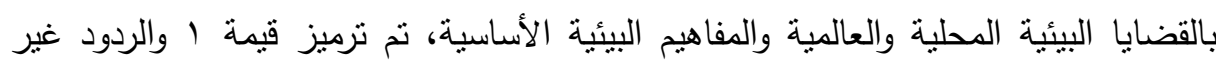
الصحيحة صفر ، كانت النتيجة القصوى لبعد المعرفة 1 ( ، وكانت النتيجة الدنيا صفر ، والدرجة

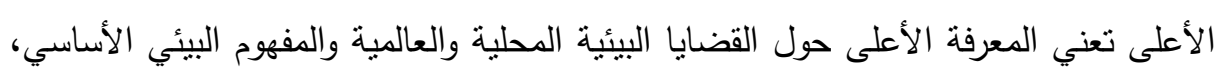
وكان معامل الاتساق الداخلي لبعد المعرفة (7^, · · ) باستخدام معامل ألفا كرونباخ.

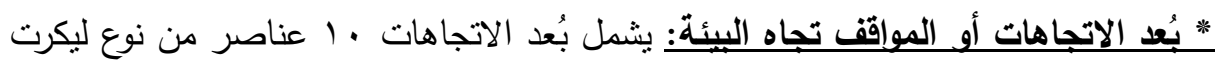

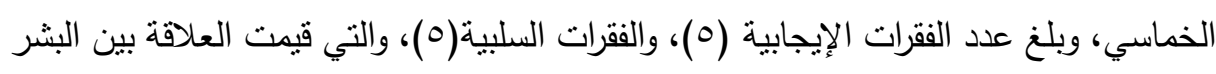

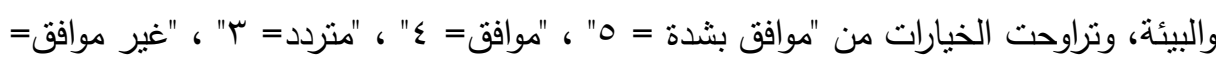

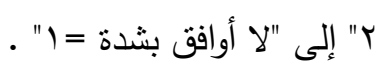

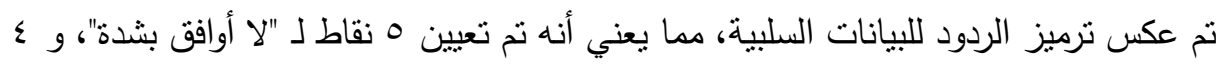

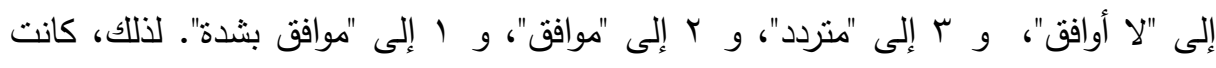

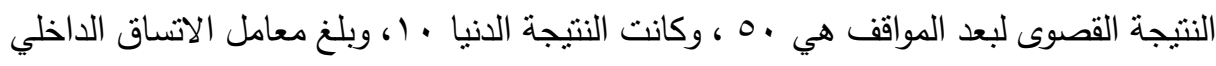

$$
\text { لبُعد المواقف( § ب, · ) ) باستخدام معامل ألفا كرونباخ. }
$$

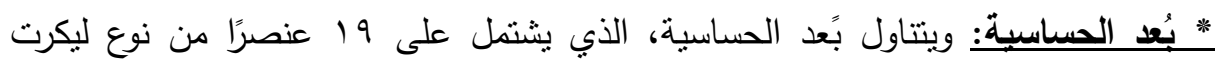

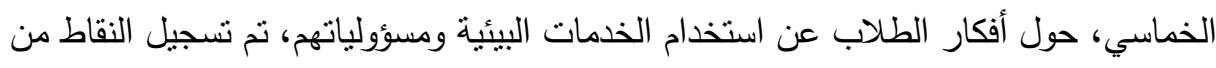
ا (لا أوافق بثدة) إلى ه (موافق بشدة)، كانت الدرجة القصوى لبعد الحساسية هي 90، وكان الحان

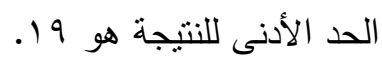

النتيجة الأعلى تعني الحساسية الأعلى تجاه البيئة، وبلغ معامل الاتساق الداخلي لبُعد الحساسية

$$
\text { ليكون(V0, · · ) باستخدام معامل ألفا كرونباخ. }
$$

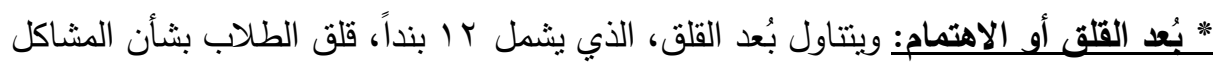

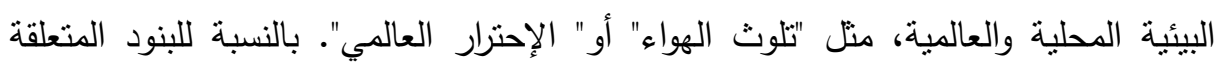


بمجموعات اختيار الرد من نوع ليكرت، تم تعيين 0 نقاط لـ "قلق شديد" ، ـ إلى "معني إلى حد

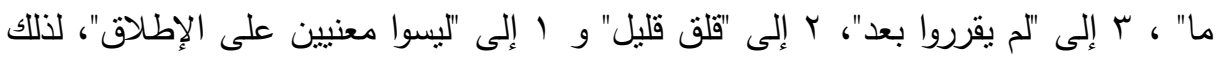

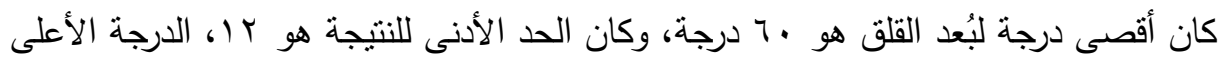

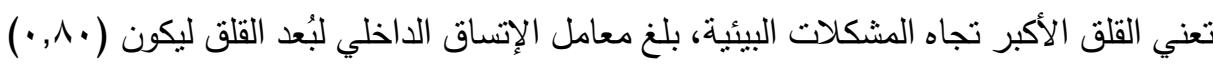
باستخدام معامل ألفا كرونباخ. نيأ. يمثل الجدول التالي عدد العناصر الموجودة في مقياس التتور البيئي لكل بُعد (المعرفة، والاتجاهات، والحساسية، والقلق)، ومعاملات الاتساق الداخلي لكل بُعد من أبعاد التتور البيئي باستخدام معامل ألفا كرونباخ. معاملات ألفا كرونباخ وعدد عناصر أبعاد مقياس التنور البيئي

\begin{tabular}{|c|c|c|}
\hline عدد الققرات & الموثوقية & البُعد \\
\hline 18 & 0.68 & المعرفة \\
\hline 10 & 0.64 & الاتجاهات \\
\hline 19 & 0.75 & الحساسية \\
\hline 12 & 0.80 & القلق ( الاهتمام ) \\
\hline
\end{tabular}

r- عرض أدوات القياس السابقة علي مجموعة من السادة المحكمين لإجراء التعديلات اللازمة وذللك للوصول للصورة النهائية لها. ع- التطبيق القبلي لكل من: استبيان الوعي البيئي، مقياس التتور البيئي علي العينة محل الدراسة للوقوف علي مستوي النتور البيئي لديهم قبلياً. ه- التطبيق البعدي لمقياس النتور البيئي علي العينة محل الدراسة للوقوف علي للي مستوبي التنور البيئي لديهم بعدياً.

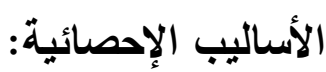
أ- الإحصاء الوصفي: في هذا الجزء، من أجل استبيان التوعية ومقياس التتور البيئي؛ نت

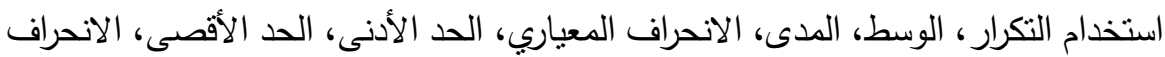

$$
\text { كإحصائيات وصفية. }
$$


ب- نتائج الإحصاء الاستدلالي: في هذا الجزء ، ينم رصد نتائج مقياس "ت- عينة مرنبطة" )

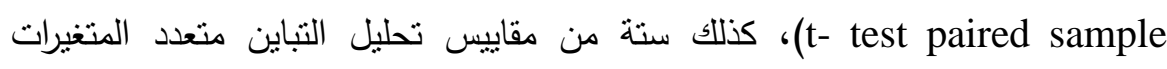

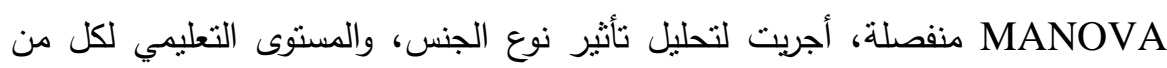

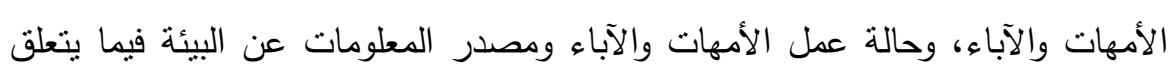
بالتتور البيئي للطلاب، وبالإضافة إلى ذلك للتحقق من العلاقة المنبادلة بين تقييم الطلاب

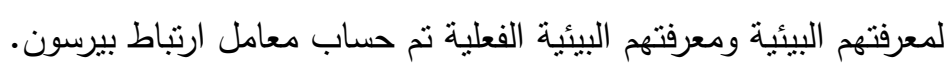

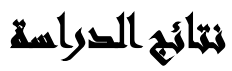

يمكن تلخيص النتائج الإحصائية الدراسة الحالية على النحو التالي:

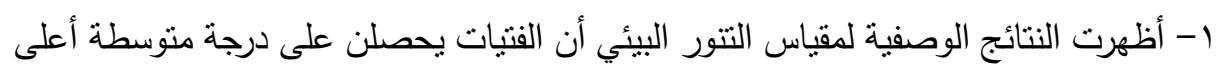
في بُعدين من أبعاد التتور البيئي وهما بُعدي المعرفة والقلق ، في حين أن البنات والبنين

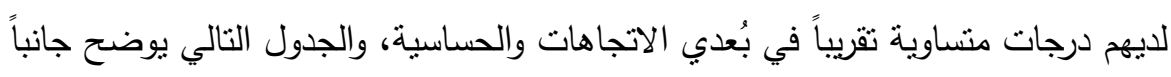
من نلك النتائج:

جدول: منوسطات وانحرافات معيارية أبعاد التنور البيئي بالنسبة للنوع

\begin{tabular}{|c|c|c|c|c|c|c|c|c|}
\hline \multicolumn{9}{|c|}{ أبعاد التنور البيئي } \\
\hline هتمام ) ( ) & القلق (الا & & الحساسي & & الاتجاهان & & المعرفة & \\
\hline إنحراف & متوسط & انحراف & متوسط & انحراف & متوسط & انحراف & متوسط & 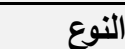 \\
\hline 6.37 & 51.63 & 7.87 & 74.52 & 5.08 & 38.06 & 3.28 & 9.55 & طالبة \\
\hline 6.89 & 49.74 & 9.39 & 74.92 & 6.19 & 38.24 & 3.48 & 9.08 & طالب \\
\hline 6.70 & 50.66 & 8.68 & 74.72 & 5.67 & 38.16 & 3.39 & 9.31 & المجموع \\
\hline
\end{tabular}

r- كثفت النتائج الاستدلالية لمقياس النتور البيئي أن هناك تأثير ذو دلالة إحصائية لتعزيز

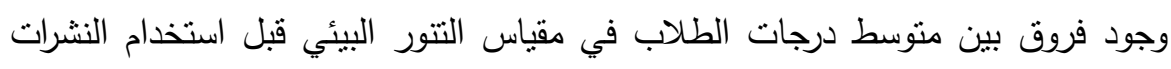
الدورية وبعد استخدامها لصالح استخدام النشرات الدورية، مما يعني أن تأثير استخدام النشرات تأثثر فعلي يرفع من متوسط الدرجات للطلاب في مقياس التتور البيئي، والجدول التالي يوضح ذلك: 
نتائج مقياس" ت- عينة مرنبطة " ( (t- test paired sample الفروق بين منوسط الدرجات الكلية للطلاب قبلياً وبعدياً

\begin{tabular}{|c|c|c|c|}
\hline Sig. $(p)$ & $t_{\text {calc. }}$ & d.f.)) لرجات الحرية & \\
\hline $.000^{* * *}$ & $\overline{7.79}$ & 111 & لي - بعدي \\
\hline
\end{tabular}

r-كثفت النتائج الاستدلالية لمقياس التتور البيئي أنه لم يكن هناك أي تأثير يعتد به إحصائيًا

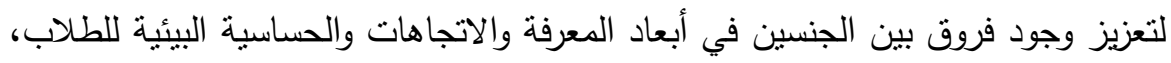
بينما يوجد فارق ذو دلالة إحصائية لوجود هذا الفرق لصالح الفتيات في بُعد القلق البيئي

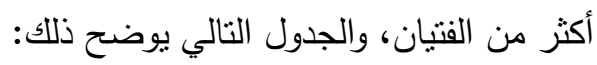

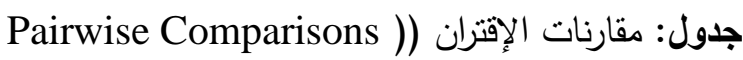

\begin{tabular}{|c|c|c|c|c|c|}
\hline$\eta^{2}$ & Sig. $(p)$ & 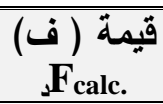 & 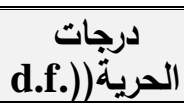 & التتغيرات & المتثغير \\
\hline 0.004 & 0.185 & 1.761 & 1 & المعرفة & \multirow{4}{*}{ الجنس } \\
\hline 0.001 & 0.529 & 0.398 & 1 & الاتجاهات & \\
\hline 0.000 & 0.841 & 0.040 & 1 & الحساسية & \\
\hline 0.018 & 0.005 & $7.961^{* *}$ & 1 & القلق & \\
\hline
\end{tabular}

ع - أظهرت نتائج تحليل التباين أحادي الاتجاه أن هنالك أثراً يعتد به إحصائياً لمستوى الأمهات

$$
\text { التعليمي في بُعد المعرفة البيئية للطلاب. }
$$

ه-وبالمثل، أوضحت نتائج تحليل التباين أحادي الاتجاه أنه كان هناك أنز يعتد به إحصائياً لمستوى الآباء التعليمي في بُعد المعرفة البيئية للطلاب.

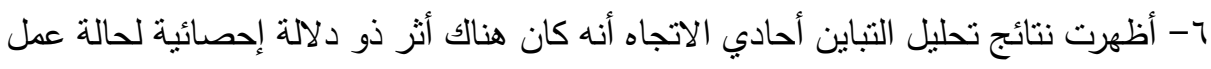

$$
\text { الأمهات على المعرفة البيئية للطلاب. }
$$

V- وعلي العكس، أوضحت نتائج تحليل التباين أحادي الاتجاه أنه لا يوجد أثر دال من الناحية

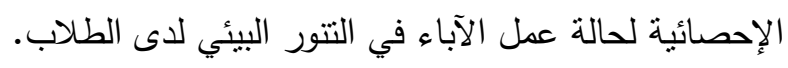




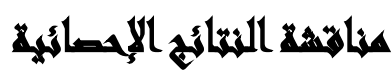

كان الهدف الرئيسي من هذه الدراسة هو تتمية بعض عناصر التتور البيئي للطلاب من

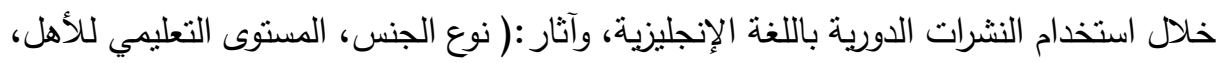

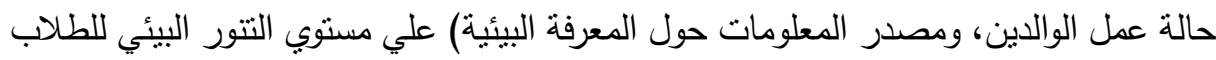
ومدي ارتباط المعرفة الفعلية للطلاب وتقييمهم الذاتي للمعرفة البيئية. وباستعراض النتائج الإحصائية نجد ما يلي: - بشكل عام، كان للطلاب الذين شاركوا في الدراسة الحالية مستويات منخفضة إلى منوسطة

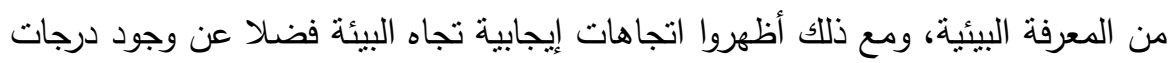

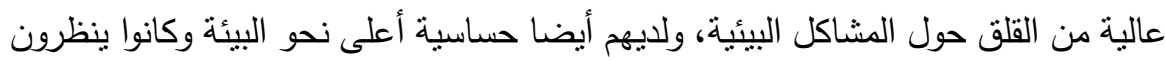
إلى المشاكل البيئية كواحدة من أهم المشاكل في حياتهم.

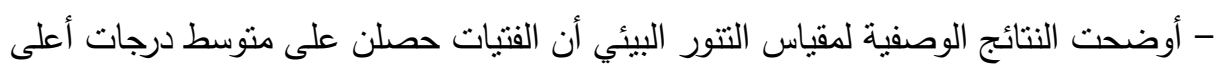

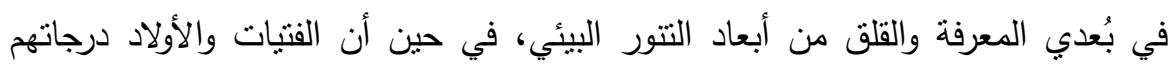
منساوية تقريباً في بُعدي الاتجاهات والحساسية.

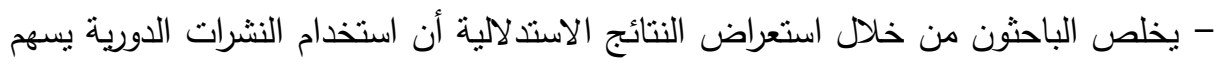
يشكل مؤثر في تتمية بعض عناصر التتور البيئي لدي الطلاب، وتحدد ذلك من خلا لله

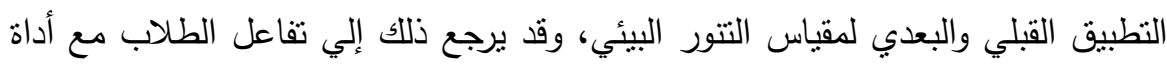

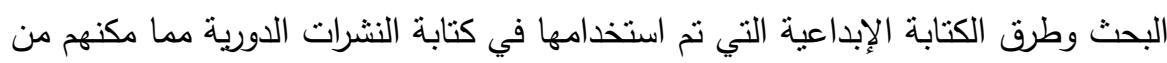

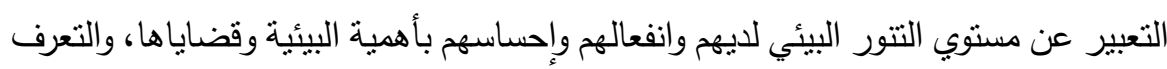
علي مكوناتها، والقضايا البيئية المحلية والعالمبة، والأخطار التي تحبط بيئتهم التي بعيشون فيها، وأهمية دورهم كأفراد ومجموعات في إنقاذ بيئتهم. - تظهر نتائج القضايا البيئية والمفاهيم البيئية أنه على الرغم من دوان أن الطلاب أجابوا بشكل

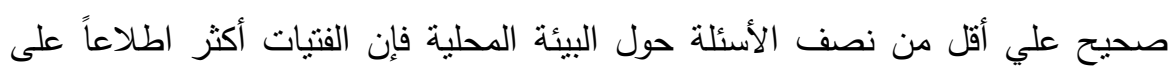
قضايا البيئة المحلية والقضايا البيئية العالمية والإيكولوجية والمفاهيم أكثر من الأولاد.

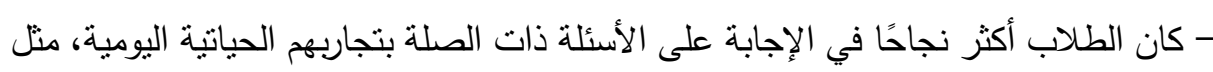
الإحترار العالمي، وإعادة التدوير، والمصادر المتجددة وانقراض الحيوانات، ومع ذلك للك فقد 
واجهوا صعوبة في الإجابة على الأسئلة التي قيمت المفاهيم الخاطئة المحتملة، فعلى سبيل

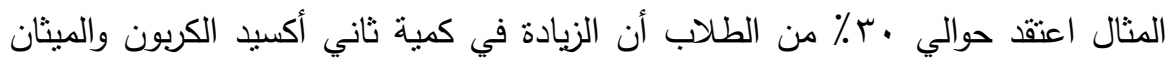
وبخار الماء في الجو تسبب في نضوب الأوزون وارتفاع درجة الحرارة، مما يشير إلى لديهم تصورات خاطئة عن استتفاد طبقة الأوزون والإحترار العالمي والخلط بين هذين المفهومين.

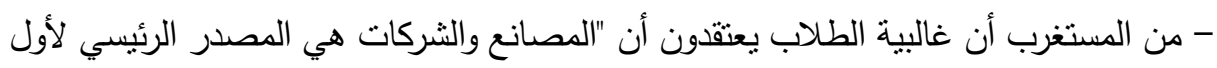

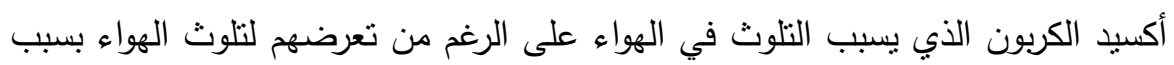
المركبات الآلية في حياتهم اليومية.

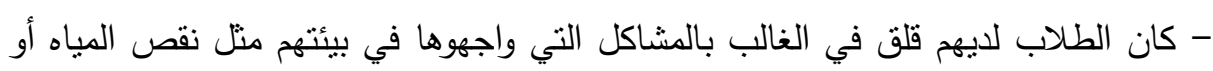
الإحترار العالمي أو إزالة المناطق الخضراء لبناء المباني والطرق.

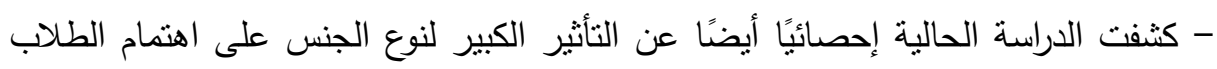

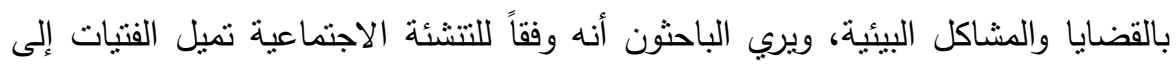
تقصص أدوار "مقدمي الرعاية" أكثر من الأولاد، مما يجعلهن أكثر قدرة على ولى فهم موقعهم

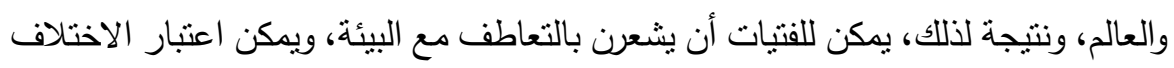

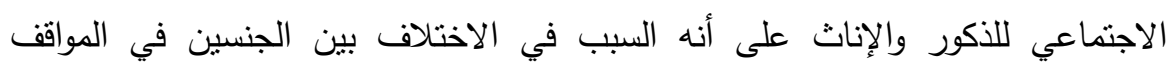
والمسؤوليات البيئية التي تتفوق فيها الإناث لكونهن أكثر إيثار ، وتعاونية، ورعاية، وترابط، الإنية في حين أن الذكور أكثر استقلالية وتتافسية. - يخلص الباحثون إلى أن مستوى قلق الإناث أكبر من الذكور عندما يتعلق الخطر على الثى

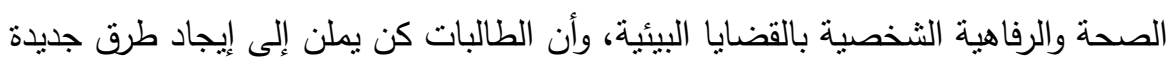

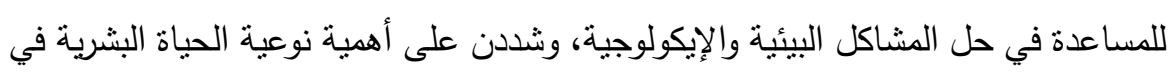
الحياة، وكانوا أكثر مسؤولية من الذكور تجاه حماية الطبيعة والبيئة، في حين يبدو أن الأولاد

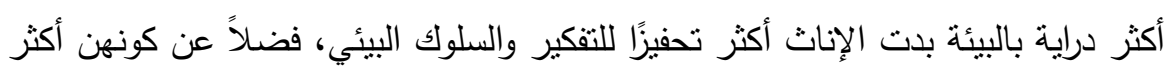

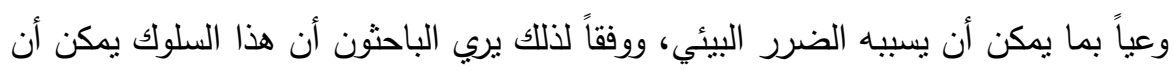

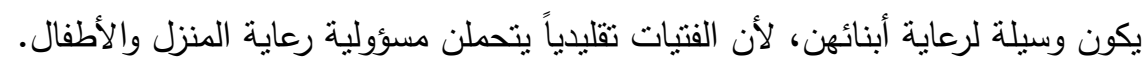




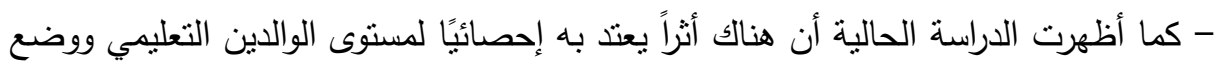

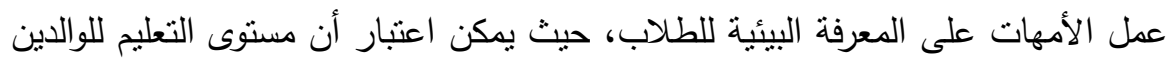

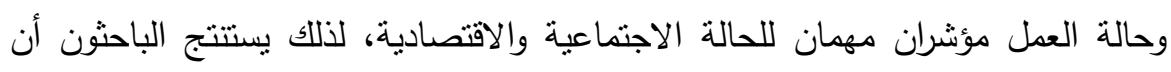
الطلاب الذين يتمتعون بوضع اجتماعي واقتصادي مرتفع هم أكثر دراية بالبيئة، وقد يكون

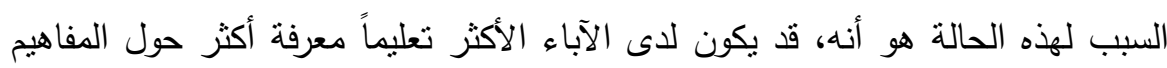

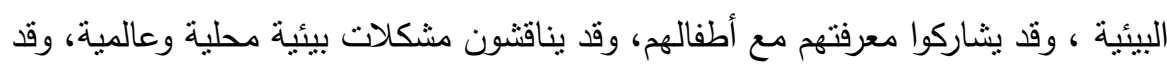
يكونون نموذجًا لأطفالهم أيضًا من خلال المشاركة في الأنشطة المتعلقة بالبيئة.

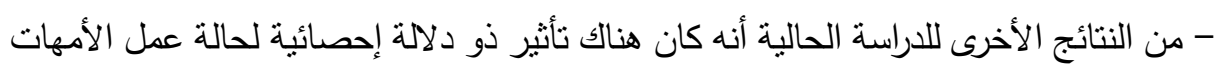

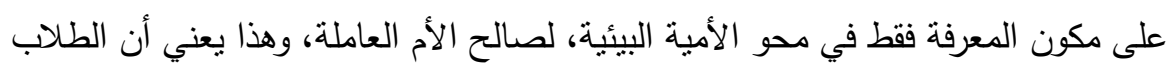

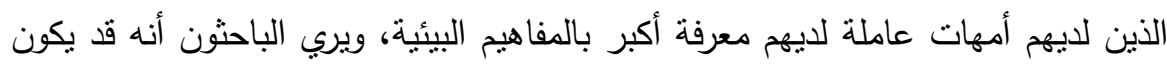

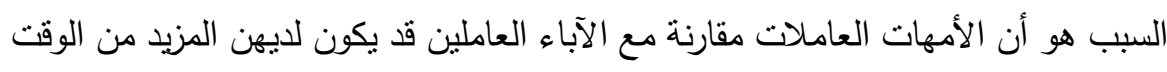
لإنفاقه مع أطفالهم، لذلك قد تكون لديهم فرصة لعقد جدل مع أطفالهم حول القضايا البيئية؛ أو الاشتراك في الأنشطة البيئية مع أطفالهن، ومع ذلك لم يكن هنالك أثز ذو دلالة إحصائية لحالة عمل الآباء على أي من مكونات محو الأمبة البيئية.

\section{المتهوياهي}

$$
\text { في ضوء هذه الدراسة يوصي الباحتون بما يلي: }
$$

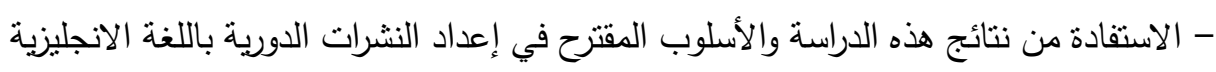

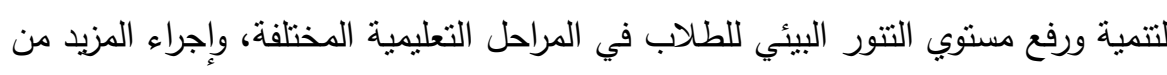

$$
\text { التعديلات المقترحة في القضايا البيئية التي تتتاولها هذه الدراسة ومثيلاتها. }
$$

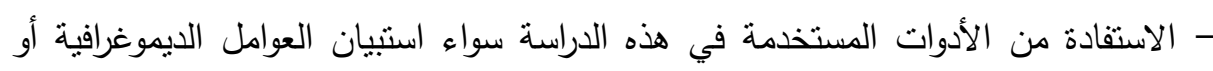

مقياس الوعي البيئي أو مقياس التتور البيئي عند إجراء المزيد من الدراسات المماثلة.

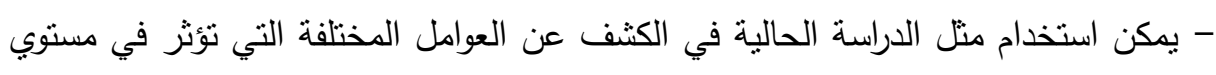
النتور البيئي لدي الطلاب، وكذلك في الكثف عن الطلاب الذين لايهم مواهب وقدرات

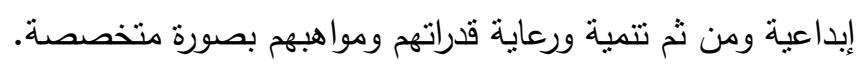


- يجب أن يتضمن المنهج الدراسي الأنشطة الفعالة التي يتمكن من خلالها المعلمون من القيام

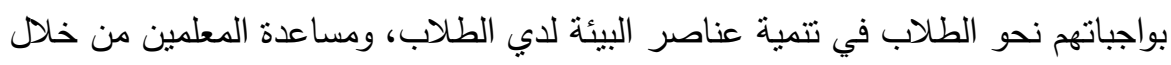
توفير الوسائل المناسبة لذلك.

- يمكن تعميم الدراسة علي مناطق سكانية مختلفة المستويات: الاجتماعية والاقتصادية والحضرية من أجل رؤية آثار المتغيرات الاجتماعية الديموغرافية على مستوى التتور البيئي لاى الطلاب.

- يمكن إجراء دراسات أخري تكثف عن مساهمة النشرات الدورية باللغة الإنجليزية في تتمية

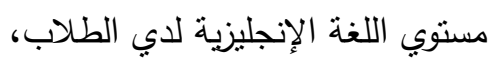

- يمكن استخدام الإعلام المدرسي، وأحد وسائله النشرات الدورية، منصة لتتمية عناصر التتور البيئي لدي الطلاب، ومن ثم تتمية واستكثاف قدراتهم لمواجهة المشكلات البيئية ومعالجتها، وإدراكهم لعلاقاتهم مع البيئة المحيطة بهم، وليس ذلك وحسب بل بل يمكن استخدام النشرات

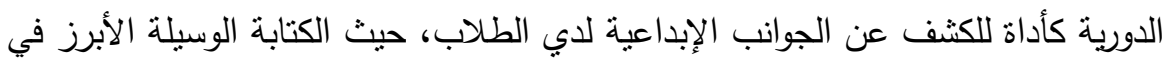
العملية التعليمية، وهي فعل إبداعي وفني يُعتبر سجلاً للتجارب المختلفة، والتي يمكن تحليلها ودراسة جوانب القوة والضعف فيها، والتي تعتبر من أهم الوسائل ليعبر المرء بها عن نفسه وأفكاره وتوجهاته وميوله.

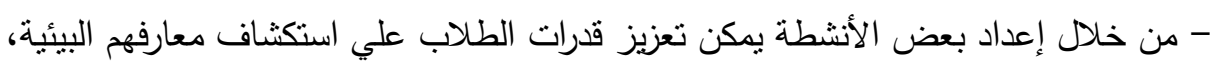

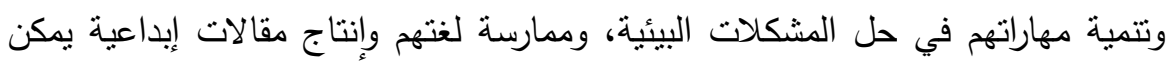

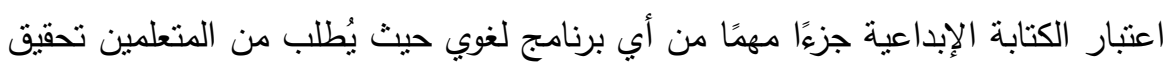
مستويات عالية من الكفاءة في اللغة التي يتم تعلمها.

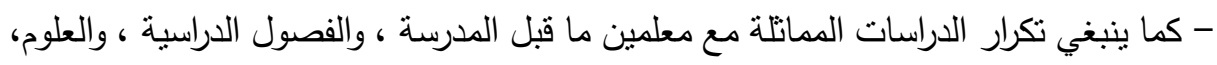
حيث يلعب المعلمون دورًا حاسمًا في تطوير معرفة الطلاب ومواقفهر وحساسيتهم

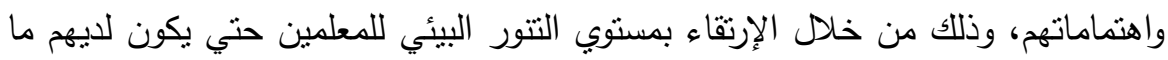

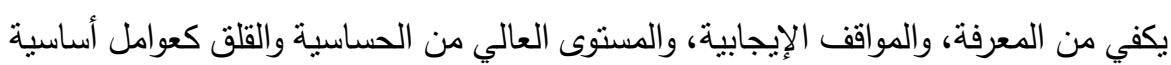
ليصبحوا نماذج جيدة لطلابهم. 


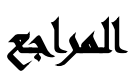

أبو خليل، فارس جميل( (1 ـ ץ): "وسائط الإعلام بين الكبت وحرية التعبير"، الأردن، دار أسامة الرافعي، محب محمود كامل(ب99 199) : "برنامج مقترح في الثقافة البيئية لبعض فئئات العاملين في مصر"، رسالة دكتوراه غير منشورة، جامعة فئ عين شمس، كلية التربية

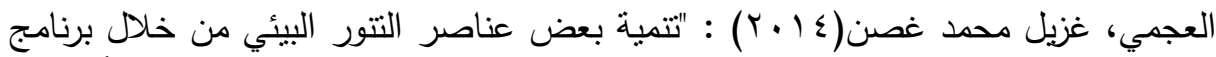
الألعاب الإلكترونية لاى تلميذات المرحلة الابندائية بدولة الكويت" لتئ، أطروحة

(ماجستير)، جامعة عين شمس، معهد الدراسات والبحوث البهات البيأية

المكاوي، حسن عماد(9 . . r): "الإعلام ومعالجة المشكلات"، مصر ، دار الفكر الجامعي رضوان، سمير : "معارك الاستنزاف بين الإنسان والبيئة"، مجلة العربي، كانون الثاني، العدد 199. • r

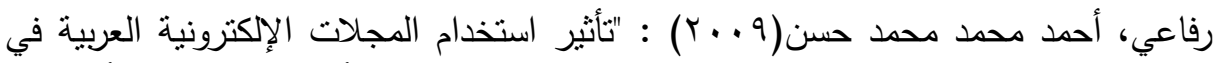

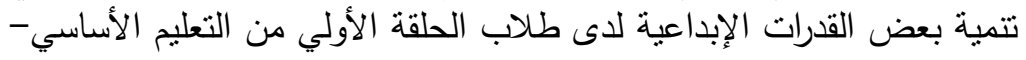

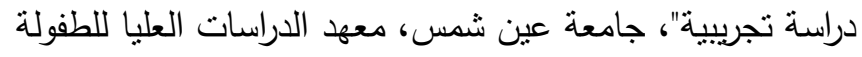

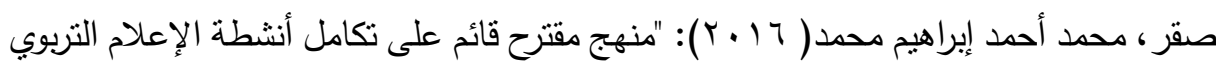

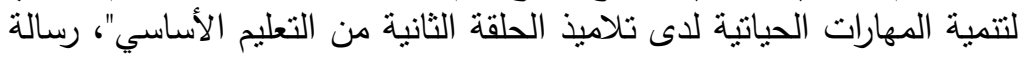

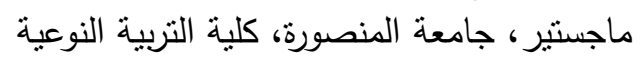

عبد السلام، عبدالسلام مصطفى: "الثقافة البيئية لدى طلاب جامعة المنصورة -دراسة ميدانية"،

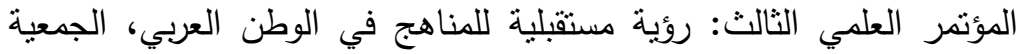

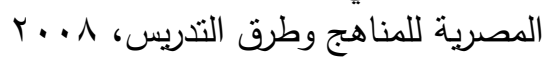

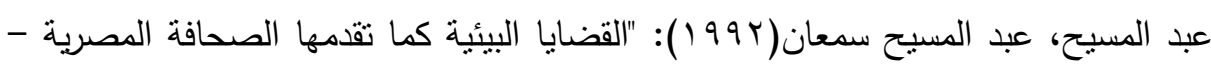

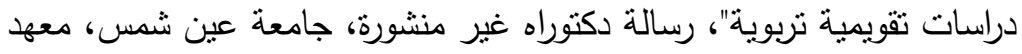
البحوث والدراسات البيئية، قسم التربية والثقافة.

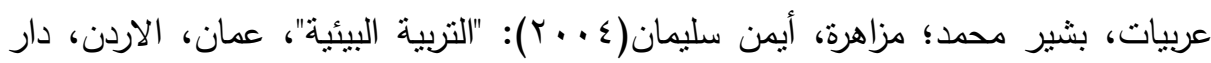

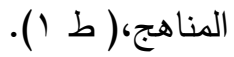

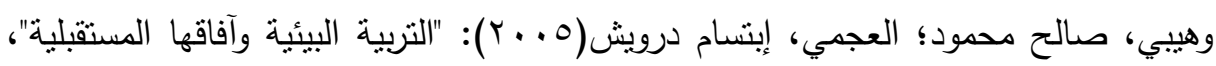

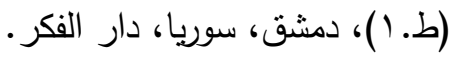


A.L.A .Glossary of library Terms. By: Elizabeth Thompson (1973),

Chicago, Illinois, Association, 12th printing. May American library, p. 99.

Allan, K. (2003): Creative Writing, Process Works, Canada.

American Association for the Advancement of science (AAAS) Science for all Americans( 1989) : A project 2061 report on Literacy goals in Science Mathematics \&Technology Washington D.C. Author.

Anderson, J.A. \& Ploghoft, M.E. (1993): Children and Media in media Education- Children and Television, Images in changing socio- cultural world, P: 91-92.

Barchers, S. (1994): Teaching Language Arts. West Publishing Company.

Bauer, T.A. (1984): " Austria: theory and practice of Media Education ". (Paris: UNESCO), P: 241-242.

Borges, J.L. (1994): On Writing. Hopewell, New Jersey, The Ecco Press. 


\title{
THE EFFECTIVENESS OF USING PERIODICALS IN ENGLISH LANGUAGE FOR DEVELOPING SOME ELEMENTS OF ENVIRONMENTAL LITERACY FOR SECONDARY STUDENTS OF LANGUAGE SCHOOLS
}

\author{
Safwat Moustafa ${ }^{(1)}$; Amira Khater ${ }^{(2)}$ and Eman S. Ali (3)
}

1) Post Gard. Institute of Environmental Studies and Research, Ain Shams University 2) Faculty of Girls, Ain Shams University 3) Educational Mass Communication, Faculty of Specific education, Ain Shams University

\begin{abstract}
The research aims to prepare Periodicals in English that include the environmental dimension, and to identify their Effectiveness in the development of elements of Environmental Literacy among Secondary school Students in Language schools, Using Creative Writing methods and strategies by allowing students to produce Periodicals themselves and under the supervision of researchers to achieve the objectives of the study, to identify whether there is influence of some demographic factors in the development of some elements of Environmental Literacy.

In the experimental study, the researchers used the following tools: Demographic Questionnaire, Environmental Awareness Scale, and Environmental Literacy Scale, which were applied to a sample of 113 secondary school students divided into an experimental sample 57 males and 56 females at "Lycee Liberty Language School" in Heliopolis Educational Administration, the research reached the Effectiveness of the proposed Periodicals in the development of some elements of Environmental Literacy among students, graver on the level of Environmental Literacy of students.

The researchers recommend to take advantage of the method proposed in this study in the preparation of Periodicals in English, which helps in developing the level of Environmental Literacy for students, and take advantage of the tools used when conducting similar studies in 332

$$
\text { المجلد الثامن والأربعون، الجزء الثالث، ديسمبر } 19
$$
\end{abstract}


different stages of education, and the dissemination of the results of this study and conducted in cultural and social areas and different educational to detect the different factors that work to develop the level of Environmental Literacy of students. 